\title{
ANALISIS KESALAHAN PENGGUNAAN TANDA BACA PADA TEKS BIOGRAFI SISWA
}

\author{
Eka Aprilia Bahrum ${ }^{1}$, Suardi Zain ${ }^{2}$, Suleha Ecca ${ }^{3}$, Nuraini Kasman ${ }^{4}$ \\ 1,2,3,4 Universitas Muhammadiyah Sidenreng Rappang \\ Jl. Angkatan 45 No 1A Lautang Salo Rappang, Pancarijang, Sidenreng Rappang \\ ekaa03564@gmail.com
}

\begin{abstract}
Abstrak: Analisis Kesalahan Penggunaan Tanda Baca Pada Teks Biografi Siswa. Penelitian ini merupakan penelitian kualitatif deskriptif yang betujuan untuk mendeskripsikan kesalahan penggunaan tanda baca yang ditemukan pada teks biografi yang ditulis oleh siswa kelas X SMA Muhammadiyah Pangsid Kecamatan Maritengangae Kabupaten Sidenreng Rappang. Data diperoleh melalui wawancara, tes tertulis, dokumentasi dan klasifikasi data kemuddian dianalisis dengan teknik pengodean (cooding), pendeskripsian tiap-tiap kesalahan, pengklasifikasian dengan menggunakan persentase, dan membuat kesimpulan mengenai kesalahan terbesar sampai yang terkecil. Kesalahan terbesar pada penggunaan tanda baca yang ditemukan pada tulisan siswa yaitu kesalahan pada penghilangan tanda titik di akhir kalimat pernyataan dengan persentase $37,77 \%$.
\end{abstract}

Kata kunci: kesalahan, menulis, tanda baca, teks biografi.

\begin{abstract}
Analysis of misue of ponctuation on the student biografical text. The study overshadows descriptive qualitative studies intended to describe misuses of the punctuation found in the biographical text written by the tenth graders SMA Muhammadiyah Pangsid District Maritengngae Municipality Sidenreng Rappang.. The data is copied trough interviews, written tests, and data klasifications, and the analysed by coding techniques, drawing conclusions regarding the biggest blunder. The biggest miscalucation on the reading mark found in student rulon is the point mark error at the end of a statment by a percentage of $37,7 \%$.
\end{abstract}

Keyword: error, biographical text, punctuation, write.

Bahasa Indonesia merupakan bahasa resmi yang digunakan baik dalam situasi formal maupun informal (Pujiatna 2018:1). Selain itu, Indonesia juga digunakan untuk pendidikan pra sekolah dari usia dini hingga pendidikan tinggi. Oleh karena itu, sebagai penutur bahasa Indonesia perlu memahami hukum penggunaan bahasa Indonesia. Karena bahasa yang benar harus mengikuti aturan penggunaan yang telah ditetapkan.

Penggunaan ejaan merupakan salah satu kaidah yang harus dihormati oleh pengguna bahasa karena konsistensi dan keragaman genre dan sangat menentukan keberhasilan bahasa tulis. Ejaan terdiri dari menulis huruf, menulis kata, menggunakan tanda baca dan serapan. Ejaan adalah hukum yang melambangkan bahasa simbolik. Oleh karena itu, ejaan adalah kaidah yang terdiri dari tata cara penulisan lambang bahasa tulis yang berkaitan dengan penulisan huruf, kata, dan lambang (Arifin dan Tasai, 2015).

Menulis merupakan kegiatan yang melibatkan penggunaan ejaan dalam menuliskan lambang-lambang (huruf) untuk menyusun kalimat menjadi sebuah paragraf seutuhnya. Kegiatan menulis adalah kegiatan penyampaian gagasan dan pikiran yang hasilnya diharapkan dapat dimengerti oleh pembaca dan berfungsi sebagai alat komunikasi secara tidak lansung (Effendi 2008: 344). Jadi, agar sebuah tulisan bisa 
menjadi sarana penyampaian gagasan pikiran yang baik dan dipahami pula dengan baik oleh pembaca, maka penggunaan ejaan pada tulisan tersebut harus tepat dan jelas. Sebaliknya, kesalahan penggunaan ejaan yang dilakukan ketika menulis, dapat menyebabkan kekaburan makna dan salah penafsiran. Hal itu membuat tulisan sebagai sarana penyampaian pesan menjadi tidak efektif.

Kesalahan penggunaan ejaan yang sering didapatkan pada tulisan siswa yaitu penggunaan tanda baca. Apabila dibandingkan dengan pemakaian huruf, penulisan huruf, penulisan kata, dan penulisan unsur serapan, pemakaian tanda bacalah yang sering mengalami kesalahan dalam tulisan siswa.

Penggunaan tanda baca merupakan bagian yang berperan penting dalam keefektifan pembentukan kalimat bahasa Indonesia. Penggunaan tanda baca yang benar dan sesuai dengan kaidah akan menyebabkan korespondensi antara bentuk dan isi tulisan. Maka dari itu, makna dalam sebuah kalimat dapat menjadi lancar dan terarah (Arifin dan Tasai, 2015: 171).

Kemampuan menggunakan tanda baca dengan cermat dan tepat oleh siswa saat menulis, merupakan suatu tuntunan yang harus dipenuhi, agar tulisan siswa dapat menjadi sarana penyampaian ide yang baik. Jadi, siswa diharapkan untuk mampu menggunakan tanda baca dengan benar ketika menulis. Oleh karena itu, sangat penting bagi siswa diberikan pelajaran tentang Pedoman Umum Ejaan Bahasa Indonesia (PUEBI) khususnya mengetahui jenis-jenis tanda baca berdasarkan masing-masing fungsinya. Supaya pada saat menulis, siswa tidak lagi merasa kesulitan dalam hal penempatan tanda baca.

Tanda baca yang terdapat pada Pedoman Umum Ejaan Bahasa Indonesia (PUEBI) ada lima belas, yaitu: 1) tanda titik $(), 2$.$) tanda koma (), 3$,$) tanda titik koma (;),$ 4) tanda titik dua (:), 5) tanda hubung (-), 6) tanda pisah (--), 7) tanda elipsis (...), 8) tanda tanya (?), 9) tanda seru (!), 10) tanda kurung $((\ldots)), 11)$ tanda kurung siku $(\{\ldots\}), 12)$ tanda petik (“...”), 13) tanda petik tunggal ('...'), tanda miring (/), dan 15) tanda penyingkat atau apostrof ('). Kelima belas tanda baca tersebut masing-masing memiliki fungsi yang berbeda dan setiap fungsinya telah dijelaskan secara mendetail di dalam PUEBI, serta keseluruhan tanda baca tersebut dapat digunakan pada saat menulis kalimat atau paragraf dengan menggunakan bahasa Indonesia.

Berdasarkan wawancara yang dilakukan penulis dengan guru bahasa Indonesia di SMA Muhammadiyah Pangsid, sehingga memperoleh informasi bahwa ternyata sebagian siswa kelas $\mathrm{X}$ belum mampu menggunakan tanda baca dengan tepat sesuai kaidah dalam tulisannya. Untuk membuktikan informasi tersebut benar atau tidak, maka perlu dilakukan penelitian tentang penggunaan tanda baca di sekolah tersebut dengan mengambil kelas $\mathrm{X}$ sebagai objek penelitian.

Pada kurikulum 2013, terdapat mata pelajaran menulis teks biografi di kelas $\mathrm{X}$ semester genap. Salah satu indikator yang ingin dicapai pada mata pelajaran tersebut yaitu mendefinisikan tentang pola penyajian ulang teks biografi serta menulis biografi mengenai sebuah tokoh yang patut diteladani. Teks biografi merupakan tulisan tentang riwayat hidup seseorang yang ditulis oleh orang lain (Rohimah, 2014: 204). Biografi tentang sesorang ditulis karena adanya keunikan dan prestasi yang dimilikinya sehingga dapat dipetik nilai-nilai kehidupan terhadap kisah yang dialami seorang tokoh yang ditulis biografinya.

\section{METODE}

Metode penelitian yang digunakan adalah kualitatif deskriftif. Desain ini merupakan rencana yang menggambarkan variabel penelitian secara objektif. Peneliti dalam penelitian ini akan mengamati secara mendalam dan melakukan analisis terhadap objek penelitian, guna menumukan kesalahan penggunaan tanda baca dalam teks biografi yang ditulis oleh siswa. Dengan demikian, penelitian ini terfokus pada kesalahan penggunaan tanda baca yang terdapat pada teks biografi siswa.. Kesalahaan penggunaan tanda baca yang dimaksud yaitu tanda titik (.), tanda koma (,), tanda titik koma (;), tanda titik dua (:), tanda hubung (-), tanda 
pisah (--), tanda elipsis (...), tanda tanya (?), tanda seru (!), tanda kurung $((\ldots))$, tanda kurung siku $(\{\ldots\})$, tanda petik (“...”), tanda petik tunggal ('...'), tanda miring (/), dan tanda penyingkat atau apostrof.

Teknik pengumpulan data yang diterapkan pada penelitian ini adalah Wawancara, tes tertulis, dokumentasi dan klasifikasi data selanjutnya hasilnya akan dideskripsikan.Pemaparan mengenai teknik pengumpulan data yang digunakan adalah sebagai berikut.

1. Wawancara

Wawancara dilakukan oleh peneliti kepada guru bahasa Indonesia di SMA Muhammadiyah Pangsid Kecamatan Maritengngae Kabupaten Sidenreng Rappang, sebagai langkah awal yang ditempuh untuk mendapatkan data yang berupa informasi mengenai kesalahan penggunaan ejaan khususnya tanda baca yang dilakukan oleh siswa kelas X SMA Muhammadiyah Pangsid Kecamatan Maritengngae Kabupaten Sidenreng Rappang.

2. Tes Tertulis

Tes tertulis ini merupakan kerja sama antara peneliti dan guru bahasa Indonesia kelas X SMA Muhammadiyah Pangsid Kecamatan Maritengngae Kabupaten Sidenreng Rappang. Tes tertulis yang akan diberikan kepada siswa yaitu tugas menulis teks biografi. Hasil tulisan siswa yang berupa teks biografi tersebut dijadikan sebagai objek dalam mencari kalimat yang mengandung kesalahan penggunaan tanda baca.

3. Dokumentasi

Dokumentasi yaitu mencari sumbersumber data tertulis di lapangan yang berkaitan dengan masalah-masalah yang diteliti, maksud data tertulis dalam penelitian ini yaitu seluruh hasil tulisan siswa yang berbentuk teks biografi. Dalam penelitian ini, peneliti mengumpulkan hasil tulisan siswa dalam bentuk teks biografi, yang selanjutnya data tersebut akan diolah dan dianalisis sehingga dapat diketahui adanya kesalahan penggunaan tanda baca pada penulisan siswa.

4. Klasifikasi Data

Klasifikasi data dilakukan untuk mendapatkan data tentang jenis kesalahan penggunaan tanda baca yang dilakukan oleh siswa saat menulis teks biografi dan mengelompokkan tiap-tiap kategori kesalahan yang sejenis. Langkah-langkah yang dilakukan dalam mengklasifikasi data adalah sebagai berikut:

a) membaca satu persatu teks biografi yang telah ditulis oleh siswa;

b) mengumpulkan sampel kesalahan yang berupa kesalahan penggunaan tanda baca yang terdapat dalam teks biografi yang menjadi objek penelitian;

c) melakukan pengklasifikasian data dengan memperhatikan jenis kesalahan penggunaan tanda baca yang menjadi data penelitian.

Setelah data memenuhi jawaban atas pertanyaan penelitian, data kemudian dianalisis dan diproses dan harus menunjukkan gambaran yang andal dan akurat tentang data lapangan. Data diperoleh dan dikumpulkan dengan wawancara, tes menulis biografi, dokumentasi, dan klasifikasi data. Teknik analisis data untuk penelitian ini diuraikan sebagai berikut.

1. Melakukan pengodean atau cooding.

Cooding merupakan tipe atau bentuk teknik analisis untuk menganalisis data dalam penelitian kualitatif yang diterapkan oleh Grounded Theori (Cresweel dalam Mawardi 2019). Cooding pada penelitian ini dilakukkan untuk memberi kode-kode pada tiap-tiap data yang termasuk dalam kategori yang sama. Kode yaitu isyarat yang dibuat dalam bentuk angka atau huruf yang berfungsi untuk memberikan petunjuk atau identitas pada suatu informasi atau data yang akan dianalisis.

Kode ini memudahkan peneliti untuk menyortir data lapangan. Tujuannya untuk memudahkan peneliti dalam memilah jenisjenis kesalahan yang dilakukan oleh siswa, termasuk menyortir jenis-jenis kesalahan dalam penggunaan tanda baca. Setelah data dikumpulkan, kesalahan yang sering dilakukan siswa saat menulis biografi diketahui. Misalnya pada kesalahan penghilangan tanda koma di antara unsur dalam suatu perincian diberi kode (A), penghilangan tanda koma di belakang ungkapan penghubung diberi kode (B), kesalahan pada penghilangan tanda titk di 
akhir kalimat pernyataan diberi kode (E) dan seterusnya.

2. Pengklasifikasian dengan menggunakan rumus berikut:

$$
\frac{F}{N} x 100 \%
$$

Keterangan:

$\mathrm{F}$ : Frekuensi kalimat yang dianalisis

$\mathrm{N}$ : Jumlah Kesalahan

100: Bilangan tetap

Hasil penelitian ini berupa deskripsi kesalahan penggunaan tanda baca yang terdapat pada teks biografi yang ditulis oleh siswa kelas X SMA Muhammadiyah Pangsid Kecamatan Maritengngae Kabupaten Sidenreng Rappang. Setelah dilakukan proses analisis terhadap tulisan siswa, ditemukan kesalahan penggunaan tanda baca yang sangat bervariasi. Adapun kode kesalahan penggunaan tanda baca yang perlu diperhatikan terdapat pada tabel 1 .

Bagian hasil penelitian ini berisi paparan hasil analisis data. Paparkan hasil penelitian sesuai tujuan/masalah yang dikaji dan prosedur yang diuraikan pada bagian

Tabel 1 Pengodean Jenis Kesalahan Penggunaan Tanda Baca pada Teks Biografi yang Ditulis oleh Siswa

\begin{tabular}{cl}
\hline Kode & \multicolumn{1}{c}{ Jenis Kesalahan } \\
\hline A & Kesalahan penghilangan tanda koma di antara unsur dalam suatu perincian. \\
\hline B & Kesalahan penghilangan tanda koma dibelakang ungkapan penghubung. \\
\hline S & kesalahan penghilangan tanda koma dibelakang keterangan.yang terdapat pada awal kalimat. \\
\hline D & Kesalahan penggunaan tanda koma di akhir kalimat pernyataan. \\
\hline E & Kesalahan penghilangan tanda titik di akhir kalimat pernyataan. \\
\hline F & Kesalahan penggunan tanda titik dibagian kalimat ditengah-tengah unsur perincian. \\
\hline G & Kesalahan penghilangan tanda titik sebagai perantara antara nama dan gelar. \\
\hline H & Kesalahan penggunaan tanda titik untuk mengapit keterangan tambahan atau keterangan aposisi. \\
\hline I & Kesalahan penghilangan tanda titik di belakang huruf dalam suatu ikhtisar. \\
\hline J & Kesalahan penghilangan tanda titik koma diakhir peincian yang berupa klausa. \\
\hline K & kesalahan penggunaan tanda hubung untuk menyambung kata yang tidak termasuk kata ulang. \\
\hline L & Kesalahan penghilangan tanda hubung pada kata yang memiliki unsur pengulangan. \\
\hline M & $\begin{array}{l}\text { Kesalahan penghilangan tanda hubung untuk menghubungkan angka yang merupakan tahun yang telah } \\
\text { diapit oleh tanda kurung. }\end{array}$ \\
\hline $\mathrm{N}$ & Kesalahan penggunaan tanda pisah untuk menandai bagian kata yang terpenggal oleh pergantian baris. \\
\hline $\mathrm{O}$ & Kesalahan penggunaan tanda petik tunggal untuk mengapit nama istilah. \\
\hline $\mathrm{P}$ & Kesalahan penghilangan tanda kurung untuk mengapit keterangan atau penjelasan.
\end{tabular}

Setelah frekuensi data yang berupa kesalahan penggunaan tanda baca yang dilakukan oleh siswa pada saat menulis teks biografi serta analisisnya diuraikan, maka
(Ilmia Rajab, 2017).

3. Membuat kesimpulan dengan cara mendeskripsikan kesalahan penggunaan tanda baca dalam bentuk persentase, dimulai dari kesalahan terbesar sampai kesalahan terkecil.

\section{HASIL DAN PEMBAHASAN Hasil Penelitian}

metode. Hasil analisis data yang disajikan berbentuk pola, karakteristik, analisis statistik, pengujian hipotesis, dan lainnya sesuai karakteristik penelitian. Sertakan tabel, diagram, gambar, atau kutipan yang diperlukan agar visualisasi hasil penelitian mudah dipahami pembaca. Metode ditulis dengan Time New Roman 11, spasi 1.

Model tabel dapat dilihat pada contoh. Tabel dibuat hanya dengan tiga garis horizontal penuh. Hindari penggunaan "tabel di atas", "tabel di bawah", "tabel berikut", tetapi langsung menunjuk ke nomor tabel (Tabel 1). 
Tabel 2 Rekapitulasi Frekuensi Kesalahan Siswa pada Penggunaan Tanda Baca Saat Menulis Teks Biografi.

\begin{tabular}{|c|c|c|c|c|c|c|c|c|c|c|c|c|c|c|c|c|c|}
\hline \multirow{2}{*}{ No } & \multirow{2}{*}{ Siswa } & \multicolumn{16}{|c|}{ Aspek Kesalahan } \\
\hline & & A & $\mathrm{B}$ & $\mathrm{C}$ & D & $\mathrm{E}$ & $\mathrm{F}$ & G & $\mathrm{H}$ & $\mathrm{I}$ & $\mathrm{J}$ & $\mathrm{K}$ & $\mathrm{L}$ & M & $\mathrm{N}$ & $\mathrm{O}$ & $\mathrm{P}$ \\
\hline 1. & RDA & - & - & - & - & - & - & - & - & - & - & - & - & - & - & - & - \\
\hline 2. & ISR & - & 2 & - & - & 2 & - & - & - & - & - & - & - & - & - & - & - \\
\hline 3. & MLA & 1 & - & - & - & - & - & - & - & - & - & 1 & - & - & 1 & - & - \\
\hline 4. & SRI & 1 & - & 1 & - & 1 & - & - & - & - & - & - & - & - & - & 1 & - \\
\hline 5. & ANQ & - & - & - & - & - & - & - & - & 1 & 1 & - & - & - & - & - & - \\
\hline 6. & MTA & - & - & - & 1 & 1 & - & - & - & - & - & - & - & - & - & 1 & - \\
\hline 7. & RMI & - & - & - & - & 4 & - & - & - & - & - & - & 1 & - & - & - & - \\
\hline 8. & APR & - & 1 & - & - & 1 & - & 1 & 1 & - & - & - & - & - & - & - & - \\
\hline 9. & KRN & - & - & - & - & 4 & 1 & 3 & - & - & - & - & 1 & - & - & - & 2 \\
\hline 10. & SNA & - & - & - & - & 1 & - & - & - & - & - & - & 1 & 1 & - & - & 1 \\
\hline 11 & SPI & - & - & - & - & 3 & - & - & - & - & - & - & 1 & - & - & - & - \\
\hline \multirow[t]{2}{*}{12} & ANA & - & 1 & - & - & 1 & - & - & - & - & - & - & - & - & - & - & - \\
\hline & & 2 & 4 & 1 & 1 & 17 & 1 & 4 & 1 & 1 & 1 & 1 & 4 & 1 & 1 & 2 & 3 \\
\hline
\end{tabular}

Sumber: data penelitian

Berdasarkan tabel 4.13 dapat diketahui jumlah kesalahan dari tiap-tiap aspek kesalahan penggunaan tanda baca yang dilakukan oleh kelas X IPA pada saat menulis teks biografi. Selanjutnya, tiap-tiap aspek kesalahan penggunaan tanda baca akan diklasifikasikan dalam bentuk presentase sebagai berikut.

1. Kode A, yaitu kesalahan penghilangan tanda koma di antara unsur dalam suatu perincian $\frac{2}{45} \times 100=4,44 \%$.

2. Kode B, yaitu kesalahan penghilangan tanda koma di belakang uangkapan penghubung $\frac{2}{45} \times 100=4,44 \%$.

3. Kode $\mathrm{C}$, kesalahan penghilangan tanda koma di belakang kata keterangan yang terdapat pada awal kalimat $\frac{1}{45} \times 100=$ $2,22 \%$.

4. Kode D, yaitu kesahan penggunaan tanda koma diakhir kalimat pernyataan $\frac{1}{45} \times 100=2,22 \%$.

5. Kode E, yaitu Kesalahan penghilangan tanda titik di akhir kalimat pernyataan $\frac{17}{45}$ $\times 100=37,77 \%$.

6. Kode F, yaitu kesalahan penggunan tanda titik dibagian kalimat ditengahtengah unsur perincian $\frac{1}{45} \times 100=$ $2,22 \%$.
7. Kode G, yaitu kesalahan penghilangan tanda titik sebagai perantara antara nama dan gelar $\frac{4}{45} \times 100=8,89 \%$.

8. Kode $\mathrm{H}$, yaitu kesalahan penggunaan tanda titik untuk mengapit keterangan tambahan atau keterangan aposisi $\frac{1}{45} \times$ $100=2,22 \%$.

9. Kode I, yaitu kesalahan penghilangan tanda titik dibelakang huruf dalam suatu ikhtisar $\frac{1}{45} \times 100=2,22 \%$.

10. Kode J, yaitu ksalahan penghilangan tanda titik koma diakhir peincian yang berupa klausa $\frac{1}{45} \times 100=2,22 \%$.

11. Kode $\mathrm{K}$, yaitu kesalahan penggunaan tanda hubung untuk menyambung kata yang tidak termasuk kata ulang $\frac{1}{45} \times$ $100=2,22 \%$.

12. Kode L, yaitu kesalahan penghilangan tanda hubung pada kata yang memiliki unsur pengulangan $\frac{4}{45} \times 100=8,89 \%$.

13. Kode M, yaitu kesalahan penghilangan tanda hubung untuk menghubungkan angka yang merupakan tahun yang telah diapit oleh tanda kurung $\frac{1}{45} \times 100$ $=2,22 \%$.

14. Kode N, yaitu kesalahan penggunaan tanda pisah untuk menandai bagian kata yang terpenggal oleh pergantian baris $\frac{1}{45} \times 100=2,22 \%$. 
15. Kode $\mathrm{O}$, yaitu kesalahan penggunaan tanda petik tunggal untuk mengapit nama istilah $\frac{2}{45} \times 100=4,44 \%$.

16. Kode $P$, yaitu kesalahan penghilangan tanda kurung untuk mengapit keterangan atau penjelasan $\frac{3}{45} \times 100=$ $6,66 \%$.

\section{PEMBAHASAN}

Berdasarkan persentase data di atas, dapat dlihat bahwa kesalahan penggunaan tanda baca yang paling banyak ditemukan pada tulisan siswa terdapat pada kode E yaitu kesalahan penghilangan tanda titik di akhir kalimat pernyataan dengan jumlah persentase $37,77 \%$, kemudian kesalahan yang jumlah persentasenya termasuk dalam kategori menengah terdapat pada kode $G$ yaitu kesalahan penghilangan tanda titik sebagai perantara antara nama dan gelar $8,89 \%$, Kode L yaitu kesalahan penghilangan tanda hubung pada kata yang memiliki unsur pengulangan $8,89 \%$, dan kode $\mathrm{P}$ yaitu kesalahan penghilangan tanda kurung untuk mengapit keterangan atau penjelasan 6,66\%. Sedangkan kesalahan yang memiliki jumlah persentase terkecil terdapat pada kode $\mathrm{C}$ yaitu kesalahan pada penghilangan tanda koma di belakang kata keterangan yang terdapat pada awal kalimat 2,22\%, kode D yaitu kesalahan penggunaan tanda koma diakhir kalimat pernyataan $2,22 \%$, kode $\mathrm{F}$ yaitu keslahan penggunaan tanda titik di tengah-tengah kalimat di antara unsur perincian 2,22\%, kode $\mathrm{H}$ yaitu kesalahan penggunaan tanda titik untuk mengapit keterangan tambahan atau keterangan aposisi 2,22\%, kode I yaitu kesalahan pada penghilangan tanda titik dibelakang huruf dalam suatu ikhtisar 2,22\%, kode $\mathbf{J}$ yaitu kesalahan pada penghilangan tanda titik koma diakhir peincian yang berupa klausa 2,22\%, kode $\mathrm{M}$ yaitu kesalahan pada penghilangan tanda hubung untuk menghubungkan angka yang merupakan tahun yang telah diapit oleh tanda kurung $2,22 \%$, kode $\mathrm{N}$ yaitu kesalahan penggunaan tanda pisah untuk menandai bagian kata yang terpenggal oleh pergantian baris 2,22.

\section{PENUTUP}

Adapun kesimpulan dari hasil pengumpulan data dan analisis data tentang kesalahan penggunaan tanda baca pada teks biografi siswa kelas X SMA Muhammadiyah Pangsid Kecamatan Maritengngae Kabupaten Sidenreng Rappang, sebagai berikut.

Kesalahan terbesar yang ditemukan yaitu kesalahan pada penghilangan tanda titik di akhir kalimat pernyataan dengan persentase $37,77 \%$, kemudian kesalahan yang jumlah persentasenya termasuk dalam kategori menengah terdapat pada kode G yaitu kesalahan penghilangan tanda titik sebagai perantara antara nama dan gelar $8,89 \%$, Kode L yaitu kesalahan penghilangan tanda hubung pada kata yang memiliki unsur pengulangan $8,89 \%$, dan kode $\mathrm{P}$ yaitu kesalahan penghilangan tanda kurung untuk mengapit keterangan atau penjelasan $6,66 \%$. Sedangkan kesalahan terkecil yaitu kesalahan penghilangan tanda koma di belakang kata keterangan yang terdapat pada awal kalimat 2,22\%, keslahan penggunaan tanda titik di tengah-tengah kalimat diantara unsur perincian 2,22\%, kesalahan penggunaan tanda titik untuk mengapit keterangan tambahan atau keterangan aposisi $2,22 \%$, kesalahan pada penghilangan tanda titik dibelakang huruf dalam suatu ikhtisar 2,22\%, kesalahan pada penghilangan tanda titik koma diakhir peincian yang berupa klausa 2,22\%, kesalahan pada penghilangan tanda hubung untuk menghubungkan angka yang merupakan tahun yang telah diapit oleh tanda kurung 2,22\%, dan kesalahan penggunaan tanda pisah untuk menandai bagian kata yang terpenggal oleh pergantian baris 2,22\%. 


\section{DAFTAR PUSTAKA}

Anwar, Efendi. 2008. Bahasa dan Sastra dalam Berbagai Perpekstif. Yogyakarta: Tiara Wacana.

Arifin, EZ., dan Tassai SA. 2015 Cermat Berbahasa Indonesia Perguruan Tinggi. Jakarta: Akapres.

Hasrianti, A. (2021). Analisis Kesalahan Penggunaan Tanda Baca dalam Karangan Peserta Didik. Jurnal Onoma: Pendidikan, Bahasa, Dan Sastra, 7(1), 213-222. https://doi.org/10.30605/onoma.v7i $\underline{1.618}$

Mawardi, Risal. 2019. Penelitian Kualtatif Pendekatan Grouded Theori. https://dosen.perbanas.id/penelitian -kualitatif-pendekatan-groundedtheory/ (diakses tanggal 12 Januari 2020).

Pujiatna, Tri. 2018. Penguasaan Ejaan Bahasa Indonesia dalam Kemampuan Menulis Mahasiswa Baru Sebagai Bahan Penyusunan Silabus MKU Bahasa Indonesia Universitas Swadaya Gunung Jati Cirebon.Jurnal Pendidikan bahasadanSastraIndonesia.Vol5,N o1 http://dx.doi.org/10.33603/deiksi s.v5i1.95 (diakses tanggal 12 Desember 2019).
Puspitasari, Yeti. 2014. Analisis Kesalahan Huruf Kapital Dan Tanda Baca Pada Pragraf Deskriftip. Jurnal Fakultas Ilmu Tarbiyah Dan Keguruan.1-12, http://repository.uinjkt.ac.id/dspace /bitstream/123456789/25471/1/YE TI\%20PUSPITASARI-FITK.pdf (diakses tanggal 11 Desember 2020).

Ramdani., dan Dita Mulyani. 2016. Analisis kesalahan Penggunaan Tanda Baca Dalam Karangan Narasi. Jurnal Fakultas Bahasa Dan Sastra.1-10, http://eprints.unm.ac.id/id/eprint/41 $\underline{57}$ (diakses tanggal 12 Desember 2019).

Rajab, Ilmia. 2017. Analisis Kesalahan Penggunaan Tanda Baca dalam Menulis Teks Laporan hasil Observasi Siswa Kelas X SMA Negeri 1 Pangkajenne Kabupaten Pangkep. Skripsi. Makassar: Program Strata 1 Universitas Negeri Makassar. http://eprints.unm.ac.id/5976/1/SK RIPSI\%20ILMIA\%20RAJAB.pdf (diakses tanggal 19 Januari 2020).

Rohimah, Ima. 2014. BUPENA Bahasa Indonesia SMP/MTS Kelas VIII. Jakarta: Erlangga. 